Revista Destaques Acadêmicos, Lajeado, v. 12, n. 4, 2020. ISSN 2176-3070

DOI: http://dx.doi.org/10.22410/issn.2176-3070.v12i4a2020.2761

http://www.univates.br/revistas

\title{
A UTILIZAÇÃO DE METODOLOGIAS ATIVAS NOS CURSOS DO CENTRO DE EDUCAÇÃO PROFISSIONAL DA UNIVERSIDADE DO VALE DO TAQUARI - UNIVATES
}

\author{
Daniela Luisa Scheibel ${ }^{1}$, Maria Claudete Schorr ${ }^{2}$
}

Resumo: As metodologias ativas são técnicas inovadoras, que contribuem de forma significativa no processo de ensino e aprendizagem, as mesmas estão sendo bastante discutidas e implementadas nos planos de aula. São propostas educacionais que desenvolvem o processo de aprender, estratégias que trazem benefícios, tanto para os professores quanto para os alunos. Estes métodos fazem com que os alunos tenham uma postura ativa frente ao seu aprendizado, enquanto os docentes assumem o papel de orientador e mediador. Desta forma, o presente estudo teve como objetivo, verificar se as metodologias ativas estão sendo executadas nos dezessete cursos, oferecidos pela Educação Profissional da Universidade do Vale do Taquari - Univates, através de uma pesquisa qualitativa e quantitativa. O levantamento de dados foi processado por meio de dois questionários elaborados no Google Forms, sendo um para professores e um para alunos. A pesquisa foi realizada com 41 professores e 197 alunos. Com as informações, foi possível identificar que a utilização das metodologias ativas, que tem por finalidade, contribuir com o ensino e aprendizagem, são fundamentais para acompanhar a nova geração de alunos e que, já estão sendo adotadas por parte de alguns professores, mas que o aprimoramento destas estratégias não deve cessar, a busca pela qualificação deve ser constante.

Palavras-chave: Metodologias ativas. Educação Profissional. Ensino.

\section{INTRODUÇÃO}

A aplicaçãodemetodologias ativas no processodeensino eaprendizagem, vem sendo bastante discutida e empregada, são técnicas inovadoras que contribuem de forma significativa na aquisição de conhecimentos. A busca pelo aperfeiçoamento do plano de aula utilizando estas metodologias e a tentativa de alcançar resultados positivos é um grande desafio, em épocas de

1 Acadêmica do Curso de Pós-Graduação Lato Sensu - Especialização em Docência na Educação Profissional da Univates.

2 Docente da Universidade do Vale do Taquari - Univates. Doutora em Informática na Educação. 
crises e transformações não somente políticas e sociais, mas também científicas e pedagógicas (GEMIGNANI, 2012).

Estes desafios contribuem de forma positiva no processo de ensino e de aprendizagem, por isso estão sendo exigidas e implementadas nos planos de aula e projetos pedagógicos. As estratégias de ensino orientadas por método ativo trazem benefícios tanto para os professores quanto aos alunos (DIESEL; MARCHESAN; MARTINS, 2016).

Conforme Souza, Iglesias e Filho (2014, p. 285):

Os métodos inovadores de ensino-aprendizagem mostram claramente o movimento de migração do "ensinar" para o "aprender", o desvio do foco do docente para o aluno, que assume a co-responsabilidade pelo seu aprendizado.

São nestas novas propostas educacionais, combinadas aos métodos tradicionais, que acontece a valorização do aprender a aprender, o desenvolvimento da autonomia individual e da habilidade de comunicação (SOUZA; IGLESIAS; FILHO, 2014).

Neste contexto, o presente estudo teve como objetivo, investigar se as metodologias ativas estão sendo aplicadas no Centro de Educação Profissional da Univates, e qual a percepção de professores e alunos sobre a realização das mesmas. Na próxima seção, serão abordados tópicos importantes sobre o tema deste estudo.

\section{A IMPORTÂNCIA DA QUEBRA DE PARADIGMAS E NOVAS ATITUDES NA EDUCAÇÃ̃O}

Os alunos já não são mais os mesmos de épocas anteriores, eles se apresentam como sujeitos particulares, específicos, com identidades e opiniões próprias (SOBRINHO, 2010). Se os alunos não são mais os mesmos, se existe um novo tempo, são necessárias novas atitudes na educação para uma aprendizagem efetiva. Segundo Cortella (2003), existe certa resistência por parte de alguns professores quando se fala em mudanças no processo de ensino e aprendizagem, mas para acompanhar a velocidade das mudanças, paradigmas devem ser quebrados, desenvolvendo assim novas habilidades para acompanhar o ritmo de transformações e alcançar sucessos futuros.

As alterações obrigam os educadores a terem um olhar crítico, que percebam as alterações para reorganizar a maneira de trabalho. Não é necessário deixar de fazer o que se fazia, mas sim acompanhar as mudanças para que se tenha um efetivo aprendizado, estes novos métodos de aprendizagem são diferentes, por isso a necessidade de maturação e mudança (CORTELLA, 2003). 


\subsection{TÉCNICAS INOVADORAS PARA ACOMPANHAR AS MUDANÇAS}

As transformações que estão acontecendo necessitam de pessoas cada vez mais qualificadas, com perfis diferenciados. Assim, aspectos relativos à formação com perfil criativo, inovador e autônomo devem ser colocados em execução. Dessa forma, as instituições, independente do nível de ensino, precisam oferecer currículo que levem a formação destes especialistas. Para isso, é essencial que os métodos tradicionais, baseada unicamente na transmissão de conteúdos pelo professor, precisam dar espaço a este ensino inovador (DIESEL; MARCHESAN; MARTINS, 2016). Para atender estas necessidades e atingir os resultados esperados, é importante usar metodologias ativas como estratégias ou recursos de ensino e de aprendizagem. Estas metodologias, visam alcançar e motivar o aluno, diante de um problema, a se deter, examinar, refletir, relacionar a sua história, dando uma nova definição a suas descobertas (MITRE et al., 2008).

Para Souza, Iglesias e Filho (2014), a combinação de propostas, método tradicional e técnicas inovadoras, pode ser uma excelente estratégia no processo de ensino e aprendizagem.

Nas técnicas inovadoras, o professor atua como mediador, motivador e facilitador dos processos de ensino e aprendizagem, fazendo o papel de estimulador da problematização da realidade, à constante reflexão e ao trabalho em equipe, possibilitando que o aluno passe a ser o centro do processo (ativo) e que promove a sua autonomia e consequentemente o aprendizado (DIESEL; MARCHESAN; MARTINS, 2016).

Estes processos de aprendizagem, aplicados na educação profissional fazem com que os alunos tenham uma maior assimilação e fixação de conhecimentos.

\subsection{METODOLOGIAS ATIVAS DE ENSINO E APRENDIZAGEM}

Para Moran (2007), as metodologias ativas são a nova maneira de aprender, por novos caminhos, com novos participantes (protagonistas), integrando novas competências, auxiliando no aprender de forma efetiva para acompanhar os diversos ritmos, métodos, tecnologias a fim de construir alunos plenos em todas as dimensões.

Os métodos ativos são propostas interessantes, que possibilitam ao aluno assumir postura ativa frente ao aprendizado (COSTA, 2014).

Metodologias Ativas baseiam-se em formas de desenvolver o processo de aprender, utilizando experiências reais ou simuladas, visando às condições de solucionar, com sucesso, desafios advindos das atividades essenciais da prática social, em diferentes contextos (BERBEL, 2011, p.29). 
A própria vivência escolar possibilita perceber que existem diversos métodos de ensino, e essa característica varia de acordo com cada professor, que geralmente é influenciado pelo modelo de educação que ele teve (COSTA, 2014).

Assim como outros autores, Costa (2014), em seu estudo relata alguns métodos que podem ser empregados em sala de aula para facilitar o ensino e aprendizagem. Entre eles estão os trabalhos em grupos, a construção de mapas conceituais, as aulas expositivas dialogadas (superando o tradicional), as oficinas, as discussões e debates, o estudo de textos, os seminários; portfólios, o teatro, os filmes, as projeções e documentários, o ensino com pesquisa, o estudo de caso e a aprendizagem baseada em problemas.

Quando o aluno é exposto a estes desafios, como por exemplo, resolver problemas, o mesmo é impulsionado ao aprendizado, a construção do conhecimento acontece de forma mais eficiente a partir de experiências prévias vividas (FREIRE apud COSTA, 2014).

Oliveira e Araújo (2015), apresentam em seu artigo alguns exemplos de metodologias ativas como o PBL - Project Based Learning (Aprendizagem por meio de Projetos ou de Problemas).

Segundo ele:

O método Project Based Learning - PBL, ou aprendizagem baseada em projeto, vem de uma tradição pedagógica inspirada pelo filósofo americano John Dewey, segundo a qual os alunos aprendem melhor a partir da experiência e da resolução de problemas do mundo real (OLIVEIRA; ARAÚJO, 2015, p. 8).

Os autores ainda mostram o Peer Instruction (Aprendizado por Pares); TBL - Team-based Learning (Aprendizagem por Times); WAC - Writing Across the Curriculum (Escrita através das Disciplinas); Study Case (Estudo de Caso); TPS Think Pair Share (Pensamento Compartilhado em Pares); Flipped Classroom (Sala de Aula Invertida); Blended Learning (Ensino Híbrido) (OLIVEIRA; ARAÚJO, 2015).

Na próxima seção serão apresentados os procedimentos metodológicos da presente pesquisa.

\section{PROCEDIMENTOS METODOLÓGICOS}

A metodologia de análise adotada é de caráter bibliográfico, e para o desenvolvimento da pesquisa utilizou-se uma investigação de abordagem quantitativa e qualitativa. Conforme Gerhardt e Silveira (2009), os métodos qualitativos aprofundam a descrição, compreensão e explicação, não se preocupam em apresentar valores numéricos, este tipo de abordagem reproduz basicamente informações. Já na pesquisa quantitativa, os resultados são 
quantificados, as informações são compreendidas a partir de procedimentos estatísticos.

Por este motivo, o aproveitamento das duas pesquisas permite recolher mais informações do que se poderia conseguir separadamente.

Tanto a pesquisa quantitativa quanto a pesquisa qualitativa apresentam diferenças com pontos fracos e fortes. Contudo, os elementos fortes de um complementam as fraquezas do outro (GERHARDT; SILVEIRA, 2009, p.34).

A pesquisa foi efetuada através da aplicação de dois questionários, elaborados no Google Forms. Participaram das entrevistas alunos e professores, dos cursos técnicos em Saúde, Administração, Alimentos, Automação Industrial, Comunicação Visual, Edificações, Eletroeletrônica, Enfermagem, Informática, Manutenção Automotiva, Manutenção e Suporte em Informática, Química, Radiologia, Segurança do Trabalho, Serviços Jurídicos, Transações Imobiliárias e Vendas do Centro de Educação Profissional da Univates.

Como mencionado no parágrafo anterior, foram elaborados dois questionários, sendo um para professores e outro para alunos, contendo 8 e 11 questões respectivamente. Para os 114 professores que ministram disciplinas nos cursos técnicos da Univates, foi enviado por e-mail um link do questionário elaborado e somente 41 professores participaram.

Através de um sorteio foram definidas as duas disciplinas de cada curso para observância. O questionário para os alunos foi disponibilizado em sala de aula, para agilizar a coleta de informações, e auxiliar o acesso ao link foram levados chromebooks ${ }^{3}$ para que os alunos pudessem responder a pesquisa. Dos 1714 alunos matriculados nos cursos técnicos, 197 participaram do estudo.

Para apresentação dos resultados qualitativos, realizou-se a análise das respostas descritivas e para os resultados quantitativos, fez-se análise das questões objetivas dos questionários, através da tabulação dos dados e confecções de gráficos, para uma melhor análise os dados.

As informações coletadas foram analisadas, com o intuito de identificar se as metodologias ativas estão sendo praticadas, e qual a visão tanto do docente quanto do aluno sobre o uso das mesmas. Na próxima seção será apresentada a análise dos resultados da presente pesquisa.

\section{ANÁLISE DOS RESULTADOS}

Neste capítulo serão apresentados os resultados quantitativos e qualitativos levantados na pesquisa, bem como a discussão e comparação

3 Chromebook é um notebook que roda o sistema Chrome OS, desenvolvido pela Google. 
de ideias, das questões que apresentaram resultados mais relevantes para a investigação.

Os 41 professores entrevistados atuam no curso técnico da Univates, entre 6 meses e 24 anos, destes 21 são homens e 20 são mulheres. Participaram da pesquisa 107 alunos do sexo masculino e 90 alunos do sexo feminino. Dos alunos entrevistados 151 apresentam idade entre 20 a 25 anos, 19 de 25 a 30 anos, 15 entre 30 a 35 anos, e os demais acima de 35 anos.

Estes dados se referem as questões 1,2 e 3. Na sequência estão apresentadas, as questões selecionadas e os resultados das respostas do grupo citado anteriormente.

Quadro 1: Questão 4 do questionário elaborado para os professores.

Questão 4: São aplicadas metodologias ativas em suas aulas?

Fonte: Dos autores (2020).

A questão (QUADRO 1), mostrou que 95,1\% dos professores praticam metodologias ativas em suas aulas, conforme pode ser visto no Gráfico 1.

Gráfico 1. Professores que aplicam métodos ativos (QUESTÃO 4)

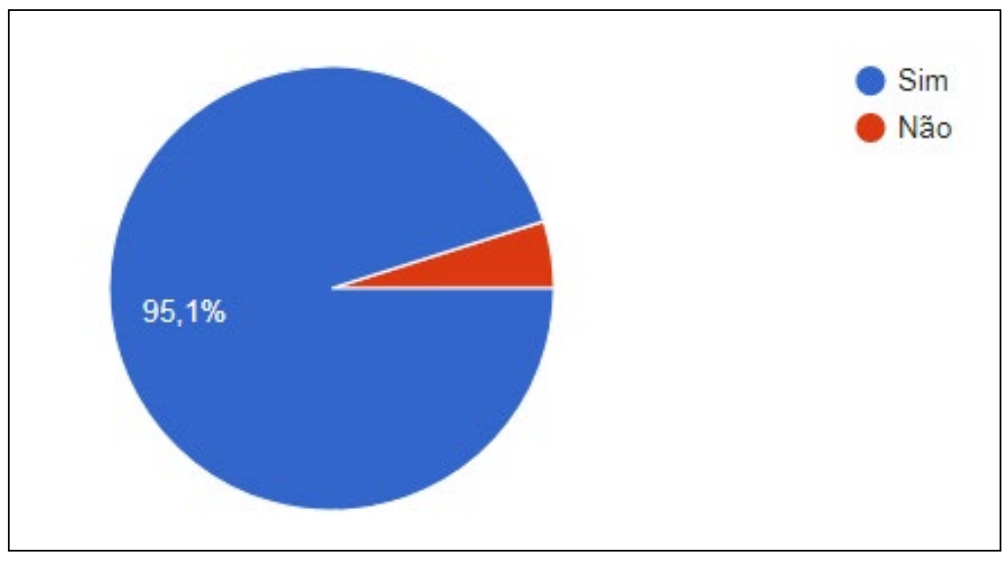

Fonte: Dos autores (2020).

Quando a mesma pergunta foi realizada aos alunos, pode-se perceber que realmente elas já estão inseridas nos planos de aulas, pois $95,9 \%$ dos alunos responderam que elas estão sendo manuseadas. Este número mostra que os professores estão inovando em seus métodos de ensino, tornando os alunos pessoas mais ativas e autônomas, pois conforme Diesel, Marchesan e Martins (2016), as metodologias ativas fazem com que o aluno seja o principal 
responsável de sua aprendizagem, este passa a ter participação ativa em sala o que faz com que ele tenha atos e construções variadas.

Quadro 2: Questão 5 do questionário elaborado aos professores

Questão 5: Como você percebe a implementação delas?

Fonte: Dos autores (2020).

Os professores que já usam as metodologias ativas responderam a questão 5 (QUADRO 2), e relataram que no início os alunos não aceitaram muito bem a proposta, pois estavam acostumados aos métodos tradicionais, mas que com o passar do tempo, aperfeiçoando os métodos de trabalho com os demais professores o cenário mudou. Embora alguns alunos ainda prefiram os métodos tradicionais, é evidente, que os resultados da realização das metodologias ativas trazem contribuições importantes no processo de aprendizagem dos alunos. É necessário nas implementações de novas metodologias, a troca de experiências entre professores, as reuniões e os planejamentos em conjunto para que se tenha resultados positivos.

O esclarecimento ao aluno e o adequado planejamento da metodologia é essencial, para que ela realmente alcance seu propósito. Nesses encontros, de acordo com Freire (2008), "ocorrem momentos de trocas de conhecimentos entre os docentes, uma ajuda mútua que proporciona a reeducação no próprio local de trabalho" (FREIRE apud MESQUITA; MENESES; RAMOS, 2016, p.481).

Quadro 3. Questão 6 do questionário elaborado aos professores

Questão 6: Que estratégias pedagógicas estão inseridas no plano de aula que facilitam o ensino- aprendizagem?

Fonte: Dos autores (2020).

Inúmeras foram as estratégias relatadas na questão 6 (QUADRO 3). As que mais são empregadas pelos professores em seus planos de aula, que facilitam o ensino e aprendizado são as revisões de conteúdo com exercícios individuais e em grupos, as aulas práticas e pesquisa, o aprendizagem baseado em problemas/projetos, a sala de aula invertida, o desenvolvimento de mapas mentais, os seminários, as aulas expositivas dialogadas, o ambiente virtual, as avaliações individuais e em grupos, as palestras, as visitas técnicas, as TIC's (tecnologias da informação e comunicação), os glossários, fóruns, os jogos interativos e as oficinas.

Estas diferentes estratégias de ensino são importantes, mas para que sejam realmente válidas e produtivas devem ser pensadas e planejadas para 
realização. É necessário sem dúvida a formação continuada dos professores para compreender e entender que a aprendizagem é única e depende do envolvimento do aluno. Sendo assim, não basta o professor fazer boas e diferentes metodologias, a aprendizagem acontece quando existe o interesse do aluno. Vale ressaltar ainda, que neste processo é necessário compreender que o cansaço e falta de tempo, são fatores que prejudicam o processo de ensino e aprendizagem, e por isso é preciso estar preparado, para enfrentar os desafios e consequentemente ter resultados positivos (COSTA, 2014).

Quadro 4. Questão 7 do questionário elaborado aos professores

Questão 7: Quais são os processos de avaliação utilizados nas disciplinas?

Fonte: Dos autores (2020).

De acordo com Cortella, (2003), diversas atividades ao longo do semestre são fundamentais para medir o aprendizado. Na questão 7 (QUADRO 4), 95,1\% dos professores responderam que não utilizam apenas uma forma de avaliação, ou seja diversas atividades são realizadas ao longo do semestre como forma avaliativa, o que é satisfatório. Os professores aproveitaram também, e relataram algumas formas de avaliação em suas aulas, entre elas o crescimento pessoal, as aulas práticas, a organização do ambiente de trabalho, a participação ativa com colocação e perguntas, elaboração de artigos científicos, estudo de caso, jogos, atividades práticas atreladas a pesquisa e o mercado de trabalho, vinculadas aos avanços da tecnologia e realidade que irão encontrar no dia a dia.

A próxima questão (QUADRO5), se refere aos projetos interdisciplinares que são excelentes projetos para construção do conhecimento (SAMPAIO, 2015).

Quadro 5. Questão 8 do questionário elaborado aos professores

Questão 8: No curso, ou mesmo nas disciplinas ministradas existem projetos interdisciplinares?

Fonte: Dos autores (2020).

Como pode ser visto no Gráfico 2, referente à questão 8 (QUADRO 5), pouco mais que a metade dos professores $(56,1 \%)$, usam atividades ou projetos interdisciplinares.

Este tipo de abordagem é extremamente importante, e mesmo que grande parte já faça execução, deveria ser mais explorada, pois estas atividades ajudam a organizar os conhecimentos, incentivam as pesquisas e estabelecem 
uma relação entre os saberes das mais diversas áreas, pois estabelece relações entre duas ou mais disciplinas (SAMPAIO, 2015). Ao relacionar conteúdos para aprofundar o conhecimento, estamos valorizando o ensino de forma dinâmica. Essa relação entre os conteúdos disciplinares é a base para um ensino mais interessante, onde uma matéria auxilia a outra.

Gráfico 2. Professores que aplicam projetos interdisciplinares

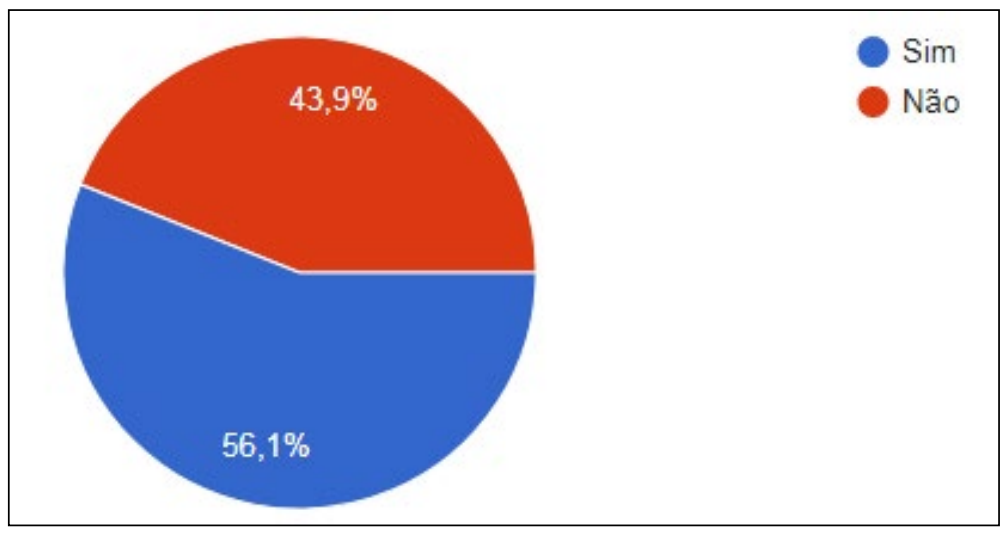

Fonte: Dos autores (2020).

Quadro 6. Questão 5 do questionário elaborado aos alunos

Questão 5: Os professores disponibilizam materiais prévios para leitura, aplicando desafios em sala de aula com base nestes materiais?

Fonte: Dos autores (2020).

A questão número 5 (QUADRO 6), se refere a ação dos professores de disponibilizar os materiais. Conforme Costa (2014), adotar desafios é uma maneira de fazer com que os alunos sejam os responsáveis pelo seu próprio aprendizado, ou seja pode ser uma das metodologias ativas fundamentais nesse processo.

Como pode ser visto no Gráfico 3, 95,9 \% dos professores em algum momento já aplicaram este tipo de metodologia e somente $4,1 \%$ dos professores ainda não colocaram em ação.

De acordo com Crouch e Mazur (apud VALENTE, 2014, p. 88):

Utilizando-se essa estratégia, foi verificado que os estudantes apresentam ganhos significativos na compreensão conceitual, avaliados com testes padronizados, bem como ganham habilidades 
para resolver problemas comparáveis aos adquiridos nas aulas tradicionais.

Gráfico 3. Professores que disponibilizam material para leitura e aplicam desafios

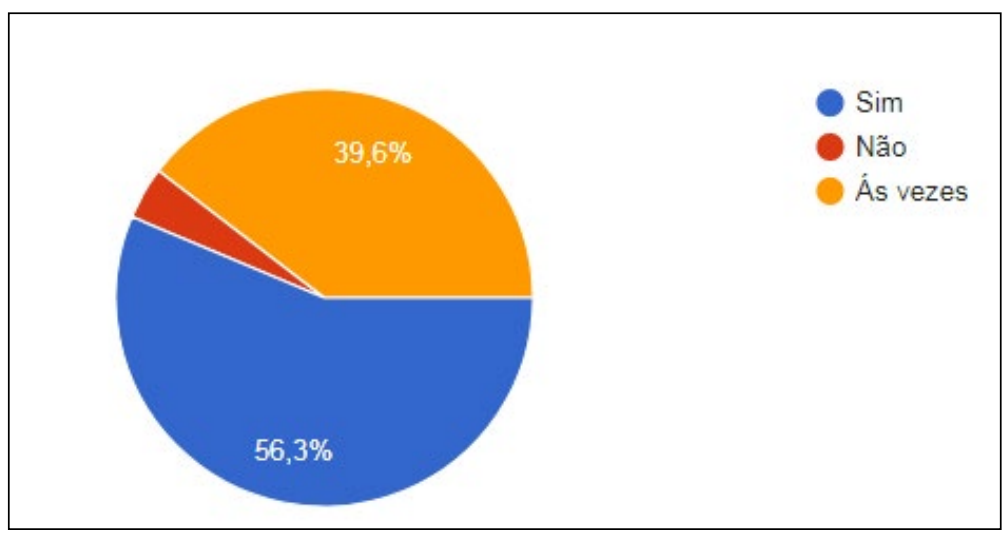

Fonte: Dos autores (2020).

Na questão 6 (QUADRO 7), os alunos foram questionados quanto ao estímulo por parte dos professores na participação de atividades no ambiente virtual.

Quadro 7. Questão 6 do questionário elaborado aos alunos

Questão 6: Os professores estimulam a participação no ambiente virtual, disponibilizando diversos tipos de materiais, como: vídeos, materiais para leituras, fóruns ou até mesmo tarefas a serem realizadas no espaço virtual?

Fonte: Dos autores (2020).

Segundo os alunos apenas $2 \%$ dos professores não estimulam a utilização do ambiente virtual, ou seja, $98 \%$ dos professores conforme Gráfico 4 , colocam esta ferramenta como forma facilitadora no processo de ensino e aprendizagem. 
Gráfico 4. Professores que estimulam o uso de ambientes virtuais

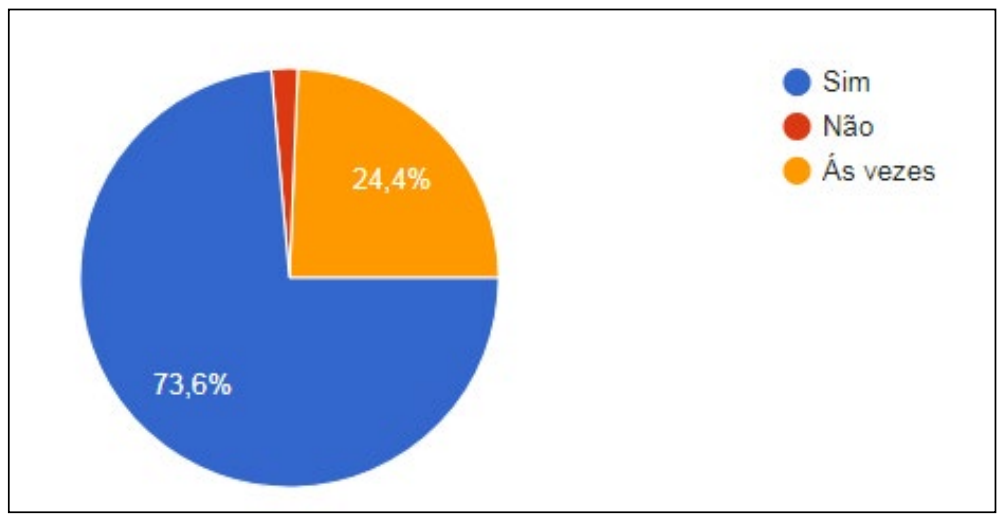

Fonte: Dos autores (2020).

Este resultado, também mostra a grande interação que existe entre os professores e alunos do centro, utilizando uma ferramenta tecnológica fundamental, pois além de facilitar o ensino e aprendizagem, tornam o ensino mais atrativo, envolvendo o aluno de forma atuante, junto com quem ensina.

Quadro 8. Questão 11 do questionário elaborado aos alunos

Questão 11: Na sua opinião, quando o processo de ensino e aprendizagem é mais eficiente?

Fonte: Da autora (2020).

Na questão 11 (QUADRO 8), 98,5 \% dos alunos entrevistados acreditam que a aprendizagem é mais eficiente quando o conteúdo é disponibilizado pelo professor em sala de aula por diferentes metodologias, quando o aluno busca seu próprio aprendizado através da mediação do professor, e quando há avaliação aproveitando diferentes técnicas. Apenas 1,5\% dos alunos entrevistados consideram métodos antigos mais eficientes onde o conteúdo é passado pelo professor por meios tradicionais, postagens de conteúdo no ambiente virtual e aulas expositivas e a avaliação do aluno se deve apenas por meio de provas individuais. Por isso, mais uma vez, vale ressaltar o quanto importante é o planejamento, garantir neste processo que a execução e a avaliação sejam eficientes para que o propósito seja alcançado.

De acordo com Moraes (2013), distribuir os conteúdos ao longo de um período, fazer testes práticos, são as maneiras mais eficazes de aprender. No entender dos pesquisadores, um teste não se limita a um instrumento de medição de conhecimento sobre um assunto. 


\section{CONSIDERAÇÕES FINAIS}

Toda proposta que tem por finalidade, contribuir com o ensino e aprendizagem, é fundamental para acompanhar a nova geração de alunos. Sem dúvida, as metodologias ativas são propostas excelentes, pois tornam o aluno ativo e responsável pelo seu aprendizado.

A partir disso, e pelo fato do método estar sendo divulgado e sugerido pelo centro dos cursos, pensou-se neste assunto, até como uma forma de incentivo e esclarecimento.

Os resultados quantitativos e qualitativos apresentados por professores e por alunos nesta pesquisa, mostram que no primeiro momento este não parece ser um dos caminhos mais fáceis, até porque toda mudança exige adaptações e ajustes, mas que quando bem aproveitadas os resultados são imensuráveis.

Pode-se observar que não existe um único método, para distribuir o conteúdo e medir o aprendizado, cada professor é livre para definir seu plano de aula, mas que é importante que ele esteja preparado para escolher as melhores opções para estimular o ensino e medir a aprendizagem.

A pesquisa também mostrou, que a grande maioria dos professores entrevistados dos cursos técnicos do Centro de Educação Profissional da Universidade do Vale do Taquari - Univates, já praticam metodologias ativas, o próprio aluno já tem observado estas mudanças, e relata ainda que o aprendizado pode ser muito mais eficiente quando a mesma é usada. Desta forma, devem ser constantes a qualificação dos professores, o planejamento e o uso de métodos ou estratégias que promovam o envolvimento e a participação ativa do aluno, no processo de desenvolvimento do conhecimento, assim contribuindo na formação de ambientes ativos de aprendizagem.

\section{REFERÊNCIAS}

\section{BERBEL, Neusi, A. N. As metodologias ativas e a promoção da autonomia}

de estudantes. Semina: Ciências Sociais e Humanas. Londrina, v. 32, n.1, 2011.

Disponível em: <http://www.uel.br/revistas/uel/index.php/seminasoc/article/ view/10326/10999>. Acesso em: 30 jul. 2017.

CORTELLA, M. S. Novos Paradigmas da Educação. 2003. Disponível em: <https:// www.youtube.com/watch?v=k0wlwV8XphY>. Acesso em: 30 jul. 2017.

\section{COSTA, F. da. Práticas de ensino inovadoras e a aprendizagem em}

ciências contábeis. 2014. Disponível em: <https:/ /www.univates.br/bdu/

bitstream/10737/783/1/2014FelipedaCosta.pdf> Acesso em: 01 jul. 2017.

DIESEL, A.; MARCHESAN, M. R.; MARTINS, S. N. Metodologias ativas de ensino na sala de aula: Um olhar de docentes da educação profissional Técnica de nível médio. 2016. Disponível em: <http://www.univates.br/revistas/index.php/signos/ article/view/1008/995>. Acesso em:13 jan. 2017. 
GEMIGNANI, E. Y. M. Y. Formação de Professores e Metodologias Ativas de Ensino- aprendizagem: Ensinar Para a Compreensão. Revista Fronteira das Educação [online], Recife, v. 1, n. 2, 2012. Disponível em: <http:/ / www.fronteirasdaeducacao. org/index.php/fronteiras/article/view/14/22>. Acesso em: 16 jan. 2017.

GERHARDT, T. E., SILVEIRA, D. T. S. Métodos de pesquisa. Porto Alegre: Editora da UFRGS, 2009. Disponível:< http://www.ufrgs.br/cursopgdr/downloadsSerie/ derad005.pdf $>$. Acesso em: 16 ago. 2017.

MESQUITA, S. K. da C.; MENESES R. M. V.; RAMOS, D. K. R. Metodologias ativas de ensino/aprendizagem: dificuldades de docentes de um curso de enfermagem. Trab. Educ. Saúde, Rio de Janeiro, v. 14 n. 2, p. 473-486, maio/ago. 2016. Disponível em: <http:/ / www.scielo.br/pdf/tes/v14n2/1678-1007-tes-1981-7746-sip00114.pdf>. Acesso em: 13 ago. 2017.

MITRE, S.M. et al. Metodologias ativas de ensino-aprendizagem na formação profissional em saúde: debates atuais. Rev. Ciência \& Saúde Coletiva, 13(sup2): 2133-2144, 2008. Disponível em:<https://www.scielo.br/scielo.php?script=sci_ arttext\&pid=S1413-81232008000900018 > . Acesso em: 15 ago. 2017.

MORAES, B. Pesquisa americana avalia métodos de estudo e aponta os mais eficazes. 2013. Disponível em: <http:/ /dc.clicrbs.com.br/sc/noticias / noticia/2013/06/pesquisa-americana-avalia-metodos-de-estudo-e-aponta-os-maiseficazes-4165724.html>. Acesso em: 15 ago. 2017.

MORAN, J. M. A educação que desejamos: novos desafios e como chegar lá. Campinas, SP: Papirus, 2007.

OLIVEIRA, A. C.; ARAÚJO, S. M. Métodos Ativos de Aprendizagem: uma breve introdução. 2015. Disponível em: <https:/ / www.researchgate.net/ publication/280091153_Metodos_Ativos_de_Aprendizagem_uma_breve_ introducao>. Acesso em: 02 ago. 2017.

SAMPAIO, C. F. Projetos interdisciplinares: concepções e práticas de docentes do ensino médio. 2015. 111 f. Dissertação (Mestrado) - Programa de pós-graduação stricto sensu mestrado em ensino do Centro Universitário UNIVATES, Lajeado, dez. 2015. Disponível em: <https://www.univates.br/bdu/ bitstream/10737/1055/1/2015ClautonFonsecaSampaio.pdf>. Acesso em: 20 ago. 2017.

SOBRINHO, A. F. O ALUNO NÃO É MAIS AQUELE! E AGORA, PROFESSOR? A transfiguração histórica dos sujeitos da educação. Faculdade de Educação Universidade de Brasília. ANAIS DO I SEMINÁRIO NACIONAL: CURRÍCULO EM MOVIMENTO - Perspectivas Atuais Belo Horizonte, novembro de 2010. Disponível em: <http:/ / portal.mec.gov.br/docman/dezembro-2010-pdf/7176-4-1-aluno-nao-emais-aquele-antonio-favero/file>. Acesso em: 30 jul. 2017.

SOUZA, C. da S.; IGLESIAS, A. G.; FILHO, A. P. Estratégias inovadoras para métodos de tradicionais - aspectos adicionais. 2014. Disponível em: <http:/ / revista.fmrp.usp. 
br/2014/vol47n3/6_Estrategias-inovadoras-para-metodos-de-ensino-tradicionaisaspectos-gerais.pdf>. Acesso em: 13 jan. 2017.

VALENTE, J. A. Blended learning e as mudanças no ensino superior: a proposta da sala de aula invertida. 2014. Educar em Revista, Curitiba, Brasil, Edição Especial n. 4/2014, p. 79-97. Editora UFPR. Disponível em: <http:/ / www.scielo.br/pdf/er/ nspe4/0101-4358-er-esp-04-00079.pdf>. Acesso em: 20 ago. 2017. 